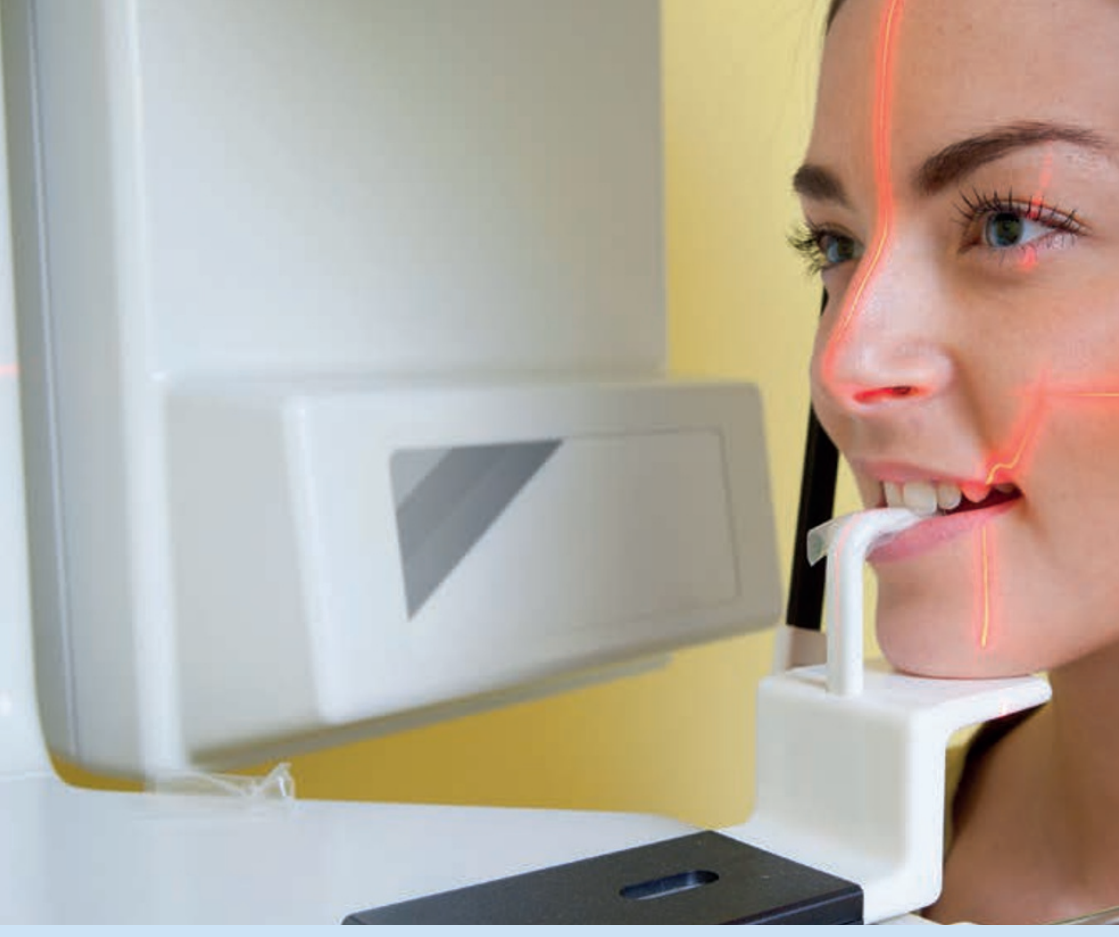

\title{
NEW REGULATIONS ON X-RAY USE: LIKELY IMPLICATIONS FOR DENTAL PRACTICES
}

\section{Professor Keith Horner, University of Manchester, Co-editor of FGDP(UK)'s Selection criteria for dental radiography, has reviewed the draft lonising Radiation Regulations 2017 and draft lonising Radiation (Medical Exposure) Regulations 2018 and what they mean for dental practices.}

$\mathrm{N}$ ew regulations relating to the use of $\mathrm{X}$-rays will come into force in early 2018. The Ionising Radiation Regulations 2017 ('IRR17') will take effect on 1 January 2018 and the Ionising Radiation (Medical Exposure) Regulations 2018 ('IRMER18') on 6 February 2018. They apply to England, Wales and Scotland. Separate regulations will be produced later for Northern Ireland.

At this stage, the regulations are still in draft format, but there are some changes that seem to be certain. In the past, a dental practice needed to notify the Health and Safety Executive (HSE), on a onceonly basis, that it was using X-rays. Under IRR17, dental practices will be required to register with HSE using an online system (under development). It is understood that registration will require confirmation that certain actions have been taken, such as appointment of a Radiation Protection Adviser (RPA), risk assessments, adequate training of staff, amongst others. There will be a fee for registration which is understood to be at the 'tens of pounds' level. Re-registration will be required on a regular basis. Other changes under draft IRR17, which might have meant dental practices having to install additional barrier protection for staff, seem to have been successfully challenged.

Under IRMER18, dental practices will need to appoint a Medical Physics Expert. It is not expected that this will be a problem as the role will almost certainly combine with that of the RPA already required to be appointed. New procedures will be required relating to justification of exposures to 'carers and comforters' (eg a parent supporting a child undergoing an X-ray examination) and, if needed, for 'non-medical imaging' (eg exposures for medico-legal examinations). Other changes seem to have minimal impact on dentists.

You should expect your RPA to update you about the changes in the months ahead. Medical and dental guidance notes are planned for publication around May 2018, unfortunately after the regulations have come into force. There are no current plans to produce a specific dental guidance document. The FGDP(UK) will update their Selection criteria for dental radiography guidance to take account of the new regulations as soon as possible and may, if it is seen to be useful, develop some additional resources to help dentists understand the new regulations.

\section{Diary}

\section{9-21 October 2017}

BDIA Dental Showcase 2017

NEC Birmingham

http://www.dentalshowcase.com/

\section{November 2017}

FGDP(UK): Holistic Dentistry: Putting the Mouth Back into the Body

National Motorcycle Museum, Solihull https://www.fgdp.org.uk/holisticdentistry

\section{3-4 November 2017}

BSDHT Oral Health Conference \& Exhibition 2017

Harrogate Convention Centre http://www.bsdht.org.uk/oral-healthconference-and-exhibition

\section{7-18 November 2017}

National Dental Nursing Conference Milton Keynes Hilton

http://badn.org.uk/conference

\section{December 2017}

BSG: Improving Mouth Care for Older People in Care Homes - Part 2 Royal College of Physicians, London https://www.gerodontology.com/ courses-and-events/

\section{January 2018}

BSDHT/BADT fundraising study day Beales Hotel, Hatfield, Hertfordshire http://bit.ly/2xACX81 